\title{
The germination niches of grassland species targeted for restoration: effects of seed pre-treatments
}

\author{
Markus Wagner*, Richard F. Pywell, Tatjana Knopp ${ }^{\dagger}$, James M. Bullock and Matthew S. Heard \\ NERC Centre for Ecology \& Hydrology Wallingford, Benson Lane, Crowmarsh Gifford, OX10 8BB, UK
}

(Received 14 July 2010; accepted after revision 6 December 2010; first published online 1 February 2011)

\begin{abstract}
Restoration of semi-natural grassland communities involves a combination of (1) sward disturbance to create a temporal window for establishment, and (2) target species introduction, the latter usually by seed sowing. With great regularity, particular species establish only poorly. More reliable establishment could improve outcome of restoration projects and increase cost-effectiveness. We investigated the abiotic germination niche of ten poorly establishing calcareous grassland species by simultaneously exploring the effects of moisture and light availability and temperature fluctuation on percentage germination and speed of germination. We also investigated the effects of three different pre-treatments used to enhance seed germination - cold-stratification, osmotic priming and priming in combination with gibberellic acid $\left(\mathrm{GA}_{3}\right)$ - and how these affected abiotic germination niches. Species varied markedly in width of abiotic germination niche, ranging from Carex flacca with very strict abiotic requirements, to several species reliably germinating across the whole range of abiotic conditions. Our results suggest pronounced differences between species in gap requirements for establishment. Germination was improved in most species by at least one pre-treatment. Evidence for positive effects of adding $\mathrm{GA}_{3}$ to seed priming solutions was limited. In several species, pre-treated seeds germinated under a wider range of abiotic conditions than untreated seeds. Improved knowledge of species-specific germination niches and the effects of seed pre-treatments may help to improve species establishment by sowing, and to identify species for which sowing at a later stage of restoration or introduction as small plants may represent a more viable strategy.
\end{abstract}

\footnotetext{
*Correspondence

Email: mwagner@ceh.ac.uk

${ }^{\dagger}$ Present address: Animal Ecology, University of Potsdam, Maulbeerallee 1, 14469 Potsdam, Germany.
}

Keywords: abiotic germination niche, calcareous grassland species, cold-stratification, osmotic seed priming, seed sowing, temperature fluctuation

\section{Introduction}

European calcareous grasslands support a diverse flora and fauna and have high conservation and cultural values (Hillier et al., 1990; WallisDeVries et al., 2002). Once widespread, they have declined massively due to agricultural intensification and abandonment, both on the European mainland (WallisDeVries et al., 2002) and in the UK (Braithwaite et al., 2006). Remaining fragments are often small and isolated from each other, resulting in an increased risk to the persistence of many of the more specialist species (Fischer and Stöcklin, 1997; Bruun, 2000). Furthermore, the effects of past habitat fragmentation on grassland biodiversity may not yet have become fully manifest (Helm et al., 2006). Both diversification of degraded sites and creation of additional semi-natural grassland are urgently required to help avert further species loss (Walker et al., 2004), and these actions are included in conservation initiatives such as the UK Biodiversity Action Plan (UK Biodiversity Group, 1998).

After extended periods of agricultural intensification or abandonment, desirable target species are often no longer present in the seed bank (Davies and Waite, 1998; Bossuyt et al., 2006; Fagan et al., 2010). Natural recolonization via seed rain or seed transfer by grazing livestock is possible if source habitats are nearby (Barbaro et al., 2001; Fagan et al., 2008). However, this process is often slow and unreliable even under favourable conditions, and frequently leads to floristically impoverished communities (Stampfli and Zeiter, 1999). Thus, active introduction is usually required (Pywell et al., 2002, 2007).

There are various methods for species introduction. Planting usually works well in terms of plant survival (Wells et al., 1989; Davies et al., 1999; Wallin et al., 2009) but is both labour- and cost-intensive. It is most often 
applied on small scales to diversify existing speciespoor vegetation (Manchester et al., 1999). If species-rich hay donor sites are available, spreading of hay from such sites can work well for hay meadow communities (Patzelt et al., 2001; Hölzel and Otte, 2003). The method tends to work less well for communities predominantly managed by grazing (Edwards et al., 2007). Because of the limitations of these alternative approaches, the most common method of introduction in grassland restoration is by sowing of seeds purchased from wildflower seed companies or collected by hand (Walker et al., 2004; Hedberg and Kotowski, 2010). However, commercial wildflower seeds are often expensive; e.g. $1 \mathrm{~kg}$ of Succisa pratensis seeds typically costs GBP 410 ( = EUR 475) (Emorsgate Seeds, 2010). Gathering of seeds from local sites, even when possible, has high labour costs and often only collects small quantities of seeds.

Even when seeds are available, efforts to re-establish target species of infertile communities often fail (Hodgson, 1989; Pywell et al., 2003). For most species, successful regeneration from seeds depends on availability of suitable establishment microsites during the species' germination season (Bakker, 1989; Schütz, 2000; Kahmen and Poschlod, 2008). For example, germination of species from unimproved grassland is usually higher in swards that are only moderately dense (Fenner, 1978). Accordingly, when diversifying agriculturally improved swards, it is common practice to carry out pre-sowing disturbance to reduce or eliminate competition by the existing sward (Isselstein et al., 2002; Hofmann and Isselstein, 2004; Pywell et al., 2007). At fertile sites, gaps created for sowing are often short-lived, as the existing sward regenerates rapidly (Pywell et al., 2007) or large numbers of seedlings of undesirable species emerge from the soil seed-bank (Galatowitsch, 2008). For these reasons, success and cost-effectiveness of restoration crucially depend on rapid and reliable seedling emergence (Pywell et al., 2003).

Many species of unimproved grassland show primary seed dormancy, i.e. their seeds are initially unable to germinate after being shed. They lose their dormancy gradually, turning from being absolutely dormant (i.e. unable to germinate at all) to being conditionally dormant (i.e. able to germinate under an initially narrow but gradually widening set of environmental conditions), and finally to being non-dormant (i.e. able to germinate under the widest possible range of environmental conditions) (Baskin and Baskin, 1998). Seed dormancy may also vary within populations, resulting in intermittent germination of many species of unimproved grassland (Olff et al., 1994). In contrast, species of agriculturally improved grassland often lack dormancy and can germinate soon after being shed (Olff et al., 1994).
Germination of non-dormant seeds is still contingent upon suitable environmental conditions, most importantly temperature, light and moisture (Schütz, 2000). Light availability and quality and diurnal temperature fluctuations commonly act as cues indicating gaps in the sward (Silvertown, 1980; Thompson and Grime, 1983; see also Bullock, 2000), and uptake of moisture enables the seeds to commence germination. As the seedling is usually the life stage most sensitive to unfavourable environmental conditions, responses to such cues can optimize timing of germination to minimize mortality (Angevine and Chabot, 1979). Similarly, intermittent germination at the population level may spread these risks in time (Cavers et al., 2000). While such adaptive germination behaviour aids persistence of plant species in their natural habitats, it may hinder species introductions during restoration, as the window of opportunity for establishment associated with pre-sowing disturbance is usually short-lived.

A wide range of pre-treatments is available to ensure rapid and complete germination and to help overcome seed dormancy (Halmer, 2004). Such pretreatments may hold great potential to improve establishment success in ecological restoration. They include seed priming techniques that allow seeds to partially hydrate and commence germination metabolism, while at the same time avoiding radicle emergence. Other pre-treatments are designed to overcome specific types of seed dormancy. For example, cold-moist stratification, i.e. exposure of imbibed seeds to cold temperatures for several weeks to months, can serve to overcome physiological seed dormancy. This is considered the most common type of seed dormancy among temperate grassland species and under natural conditions ensures germination in spring (Washitani and Masuda, 1990; Olff et al., 1994). Depending on the exact subtype of physiological dormancy operating in a species, this may be substituted by soaking of seeds in gibberellic acid solution. Results can be further improved by combining several pre-treatments (Halmer, 2004). Seed pre-treatments often widen the window of environmental conditions that will stimulate germination, and so may also affect establishment success in restoration projects.

The present study has three main objectives: (1) to investigate the abiotic germination niches of grassland restoration target species which were previously identified as difficult to establish in restoration projects; (2) to investigate the potential of various seed pre-treatments to achieve quicker and more complete germination; and (3) to investigate how pre-treatments may affect species-specific abiotic germination niches. Improved knowledge of these aspects may help increase the establishment success of such species in future restoration projects. 


\section{Materials and methods}

\section{Test species}

Ten species were included in our study (Table 1). All species occur in calcareous grassland (Rodwell, 1992) and are adapted to environmental stress associated with this habitat (Table 1). However, meta-analyses of restoration project outcomes have indicated them to be difficult to establish at grassland restoration sites (Pywell et al., 2003; R.F. Pywell, unpublished data). The only exception was Thymus pulegioides, a species less regularly used in UK restoration projects, but closely related to Thymus polytrichus, another species included in our study that establishes poorly in restoration. Bromopsis erecta performs better in restoration than the other species studied, but is still a relatively poorly establishing grass (Pywell et al., 2003). All seeds used in this study were collected in summer/autumn 2007, air-dried at room temperature and stored in darkness at $4^{\circ} \mathrm{C}$ until used for this study. Some afterripening may have occurred during storage. However, the storage regime was chosen for its similarity to storage regimes used in restoration projects (e.g. Gustafson et al., 2004; Reckinger et al., 2010). Our results thus indicate what controls germination of our target species in the context of sowing for restoration.

\section{Experimental design}

From January 2009, germination experiments were carried out using untreated seeds as well as seeds subjected to either of three different pre-treatments: (1) for cold-stratification, seeds were stored in a refrigerator at $4^{\circ} \mathrm{C}$ for 5 weeks, between two layers of nylon cloth buried in a tray filled with moist sand;
(2) osmotic seed priming was carried out by soaking seeds in a solution of polyethylene glycol (PEG)-6000 with a nominal osmotic potential of $-1.0 \mathrm{MPa}$, for which the weight ratios of PEG-6000 and distilled water were calculated with the computer program SPMM (Michel and Radcliffe, 1995); and (3) osmotic priming was also applied in combination with a seed pre-soaking in gibberellic acid $\left(\mathrm{GA}_{3}\right)$. In agricultural and horticultural species, the latter can further increase benefits associated with priming (Finch-Savage, 1991; Rogis et al., 2004). To this end, we dissolved $\mathrm{GA}_{3}$ in the PEG solution at a concentration of $1000 \mathrm{mgl}^{-1}$. For priming, seeds were placed into $90-\mathrm{mm}$ Petri dishes, with 200 seeds per dish placed on a double layer of filter paper (VWR, No. 413) soaked with $12 \mathrm{ml}$ of the respective solution. The resulting solution volume:airdry filter paper ratio exceeded the critical value of $12 \mathrm{ml} \mathrm{g}^{-1}$ above which concentration due to exclusion of PEG from filter paper is minimized (Hardegree and Emmerich, 1990). Dishes were sealed with Parafilm 'M' (Pechiney Plastic Packaging Company, Chicago, Illinois, USA). Priming was carried out in darkness for $14 \mathrm{~d}$ at $16^{\circ} \mathrm{C}$, using the incubator (MIR-253; Sanyo Electric Co., Ltd., Osaka, Japan) subsequently also used in the germination study. The selected water potential and duration are known to work well across a wide range of grassland species (Adegbuyi et al., 1981; Tallowin et al., 1994). At the end of the 5-week cold-stratification or 14-d priming periods, seeds were thoroughly rinsed in distilled water and blotted dry, and then sown into 55-mm Petri dishes containing two layers of filter paper (VWR, No. 413). We only used seeds that appeared full and undamaged, but carried out no formal assessment of seed viability. Seeds of the three smallest-seeded species (Table 1) were assessed using a stereomicroscope. Each replicate consisted of 20 seeds or, for the large-seeded B. erecta, 15 seeds.

Table 1. List of test species used in this study. Nomenclature follows Stace (1997). Seed weights from Liu et al. (2008), CSR strategy types according to Grime et al. (2007): C, competitive; S, stress-tolerant; R, ruderal. Information on primary seed dormancy types from various literature sources: ND, non-dormant; PD, physiologically dormant; PY, physically dormant; MPD, morpho-physiologically dormant

\begin{tabular}{|c|c|c|c|c|c|}
\hline Species & Family & $\begin{array}{l}\text { Seed } \\
\text { weight }(\mathrm{mg})\end{array}$ & CSR type & $\begin{array}{l}\text { Seed } \\
\text { dormancy type }\end{array}$ & $\begin{array}{l}\text { Source of dormancy } \\
\text { information }\end{array}$ \\
\hline Bromopsis erecta (Huds.) Fourr. & Poaceae & 4.63 & SC/CSR & ND & Grime et al. (1981) \\
\hline Campanula glomerata L. & Campanulaceae & 0.13 & - & PD & Hitchmough et al. (2008) \\
\hline Carex flacca Schreb. & Cyperaceae & 0.87 & $\mathrm{~s}$ & PD & Taylor (1956) \\
\hline Filipendula vulgaris Moench & Rosaceae & 0.81 & S/CSR & ND & Partzsch (2008) \\
\hline $\begin{array}{l}\text { Helianthemum nummularium } \\
\text { (L.) Mill. }\end{array}$ & Cistaceae & 1.15 & $\mathrm{~S}$ & PY & Thanos et al. (1992) \\
\hline Pimpinella saxifraga $\mathrm{L}$. & Apiaceae & 1.26 & $\mathrm{SR} / \mathrm{CSR}$ & MPD & $\begin{array}{l}\text { Flemion and Henrickson (1949); } \\
\text { Grime et al. (1981) }\end{array}$ \\
\hline Stachys officinalis (L.) Trevis. & Lamiaceae & 1.01 & S/CSR & $\mathrm{PD}^{1}$ or $\mathrm{ND}^{2}$ & $\begin{array}{l}{ }^{1} \text { Kotorová and Lepš (1999); } \\
{ }^{2} \text { Grime et al. (1981) }\end{array}$ \\
\hline Succisa pratensis Moench & Dipsacaceae & 1.30 & S/CSR & $\mathrm{PD}^{1}$ or $\mathrm{ND}^{2}$ & ${ }^{1}$ Maas (1989); ${ }^{2}$ Grime et al. (1981) \\
\hline Thymus polytrichus Borbás & Lamiaceae & 0.13 & $\mathrm{~S}$ & ND & Pigott (1955); Grime et al. (1981) \\
\hline Thymus pulegioides L. & Lamiaceae & 0.15 & - & ND & Pigott (1955) \\
\hline
\end{tabular}


In a fully factorial design, the various seed pretreatments were combined with a range of abiotic regimes involving manipulation of temperature, moisture and light conditions. Seeds were exposed either to a constant $\left(16^{\circ} \mathrm{C}\right)$ or a diurnally fluctuating $\left(12 \mathrm{~h}\right.$ at $22^{\circ} \mathrm{C}$ and $12 \mathrm{~h}$ at $\left.10^{\circ} \mathrm{C}\right)$ temperature regime which corresponds to a typical spring soil surface regime at one of our restoration sites (M. Wagner, unpublished data). Moisture was manipulated by moistening the filter paper with $4.5 \mathrm{ml}$ of either distilled water for a 'high water potential' treatment or a solution of PEG-6000 for a 'low water potential' treatment of nominally $-0.6 \mathrm{MPa}$ designed to generate moderate drought stress while still providing enough moisture to allow germination (e.g. Evans and Etherington, 1990). Again, the solution volume:airdry filter paper ratio exceeded the critical value of $12 \mathrm{mlg}^{-1}$ (Hardegree and Emmerich, 1990). For the untreated control, cold-stratification and PEG $+\mathrm{GA}_{3}$ seed priming pre-treatments, we combined these temperature and moisture regimes with three different light regimes. These were: (1) a full-light treatment with Petri dishes placed on to the top incubator shelf, lit from above by a $15 \mathrm{~W}$ fluorescent lamp for $12 \mathrm{~h} \mathrm{~d}^{-1}$, coinciding with the warmer temperature in the fluctuating temperature regime; (2) a shade treatment with Petri dishes placed on to the second shelf from the top, and dishes shaded by 'full-light' dishes and a layer of green high-density polyethylene (HDPE) shade netting $(65-70 \%$ shading) attached to the underside of the top shelf; and (3) a dark treatment with Petri dishes wrapped in aluminium foil and placed in a sealed cardboard box. During measurements with a Cropscan MSR16R sensor (Cropscan Inc., Rochester, Minnesota, USA) the green HDPE netting indeed reduced light levels across much of the visible spectrum by c. $70 \%$. The effect was stronger for red wavelengths around $660 \mathrm{~nm}$ (c. $77 \%$ reduction), but about average for far-red wavelengths around $730 \mathrm{~nm}$ (c. $71 \%$ reduction), and shading thus reduced the red/ far-red ratio of light in similar ways, but weaker, as a green leaf canopy would have done. Because of lack of time and space, germination following priming without added $\mathrm{GA}_{3}$ was tested only under full light.

Each treatment combination was replicated three times per species. Because of limited incubator space, we tested different pre-treatments in sequence. Tests with untreated seeds were started on 21 January 2009, tests with osmotically primed seeds (PEG only and PEG $+\mathrm{GA}_{3}$ ) on 4 February 2009, and tests with coldstratified seeds on 18 February 2009. The three replicate dishes of the full-light and shade treatments were stacked. To minimize solute concentration effects, dishes were sealed with Parafilm ' $\mathrm{M}$ ' after initial moistening and between counts. In addition, in the full-light and shade treatments, one-third of the solution was replaced at weekly intervals during counts.
Germinated seeds in these treatments were counted and removed after $2,5,7,9,12,14 \mathrm{~d}$ and then at $7-\mathrm{d}$ intervals until day 42 , by which time germination had ceased in most species. At each count, the topmost Petri dish of a stack was moved to the bottom, to ensure that each replicate received approximately equal amounts of light. To avoid disruption of the treatment, seed germination in darkness was recorded only once, after $42 \mathrm{~d}$. Substantial germination of Carex flacca occurred beyond the $42-\mathrm{d}$ period, and therefore monitoring of this species was continued for a further $28 \mathrm{~d}$ in the light and shade treatments, i.e. for 10 weeks in total. For B. erecta, we only tested germination of untreated seeds, as substantial germination had occurred in this species during the cold-stratification and priming pre-treatments.

\section{Data analysis}

Statistical analyses were carried out using R, Version 2.10.0 (R Development Core Team, 2009). For each species we determined general linear models that best described the dependence of final germination after 6 weeks on pre-treatments as well as abiotic conditions and their interactions with each other. To accommodate for the fact that priming without added $\mathrm{GA}_{3}$ was only assessed in the full-light regime, we ran two separate analyses per species. The seed pre-treatment analysis compared all four pre-treatment levels across the various moisture and temperature regimes at full light. The light regime analysis compared control, cold-stratification and $\mathrm{PEG}+\mathrm{GA}_{3}$ pre-treatments only, but did so across the full range of light regimes. While the latter explored the widest possible range of abiotic regimes, the former, via inclusion of both priming methods (PEG only and PEG $+\mathrm{GA}_{3}$ ) enabled assessment of whether effects of the PEG $+\mathrm{GA}_{3}$ treatment may have been caused mainly by the hydration effect of priming, the hormonal effect of $\mathrm{GA}_{3}$, or a combination.

Analysis of final percentage germination was based on arcsine-transformed data. For both the seed pretreatment and light regime analyses, we started with fully factorial maximal models including all main factors as fixed factors and all possible interactions. We then removed non-significant model terms, one at a time, beginning with the highest-order terms, and re-ran the analysis. Model simplification was stopped when all of the lower-order terms had appeared in at least one significant higher-order interaction (Crawley, 2005).

To characterize speed of germination in the fulllight and shade regimes, we calculated $t_{50}$ values, specifying time to $50 \%$ of final germination after 6 weeks in each Petri dish. For C. flacca, calculation was based on final germination after 10 weeks. 
Characterization of germination speed based on seeds that germinate per experimental unit, rather than on all viable seeds, is commonly used in seed ecological studies (e.g. Grime et al., 1981; Gibson-Roy et al., 2007).The alternative of basing calculations on $50 \%$ of all viable seeds would have required germination in different treatments to regularly exceed $50 \%$ of viable seeds, which was obviously not the case in our study. Where necessary, we interpolated between consecutive count dates. To assess treatment effects on $t_{50}$ we used the same two types of analyses as for final germination, with three differences. First, data were Box-Cox transformed prior to analysis. Box-Cox exponents were estimated using the procedure in R's MASS library. Second, as no information was available on temporal patterns of dark germination, no such data were included in the light regime analyses. Third, while General Linear Modelling (GLM) analyses were straightforward for Filipendula vulgaris, Helianthemum nummularium, T. pulegioides and T. polytrichus, all of which showed reasonable germination across the whole range of abiotic conditions, this was not the case for the remaining species. Campanula glomerata, C. flacca, Stachys officinalis, and S. pratensis germinated very poorly in the 'low water availability' treatments, and C. flacca also in the constant-temperature treatments (see Results), rendering precise estimates of $t_{50}$ impossible. Therefore, the respective subsets of treatments were not included in data analyses of $t_{50}$ for these species. By excluding complete subsets of treatments, a crossed and balanced design for analysis was maintained, and model simplification was carried out as for analyses of final germination. Due to very low final germination throughout, no $t_{50}$ values were calculated for Pimpinella saxifraga.

\section{Results}

In different species, abiotic factors and seed pretreatments tended to affect germination differently, the sole exception being soil moisture, low levels of which generally resulted in both lower final germination and reduced speed of germination $\left(t_{50}\right)$. Thus, results are reported separately for each species, with species characterized by similar germination responses being grouped.

\section{Bromopsis erecta}

Irrespective of temperature or moisture conditions, untreated seeds of B. erecta germinated to nearly $100 \%$ in full light and shade and to more than $80 \%$ in darkness. Substantial germination also occurred during seed priming and cold-stratification. It thus appears highly unlikely that low germination rates contribute to the comparatively poor performance of $B$. erecta in restoration, and so results for this species are not presented in more detail.

\section{Thymus polytrichus and Thymus pulegioides}

Germination of untreated $T$. polytrichus and T. pulegioides seeds reached $75-100 \%$ in all shading and full-light treatment combinations (Fig. 1A, B), and accordingly, there was little room for further stimulation of germination in response to seed pretreatments. Moreover, T. polytrichus showed reduced seed germination in response to cold-stratification, and this reduction was particularly pronounced at suboptimal moisture levels (Fig. 1A), which was also reflected in a significant interaction between pretreatment and moisture in the seed pre-treatment analysis (Table 2). In darkness, germination of untreated seeds was sporadic (Fig. 1A, B). However, in both Thymus species, seed priming with PEG $+\mathrm{GA}_{3}$ substituted for the light requirement for germination (Fig. 1), and this is reflected by significant two-way and three-way interactions in the light regime analyses for both species (Table 3).

Germination speed of untreated seeds was largely unaffected both by shading and by temperature fluctuation in both $T$. polytrichus and T. pulegioides (Fig. 2A, B). In the former, priming with PEG $+\mathrm{GA}_{3}$, but not without added $\mathrm{GA}_{3}$, appeared to mitigate the slowing down of germination in response to drought stress (Fig. 2A). At the same time, seeds of this species germinated more slowly after cold-stratification, particularly when moisture availability was reduced (Fig. 2A). These findings were also reflected in a significant interaction between pre-treatment and moisture level in both the seed pre-treatment analysis (Table 4) and in the light regime analysis (Table 5). In T. pulegioides, priming with $\mathrm{PEG}+\mathrm{GA}_{3}$ accelerated germination more in shaded conditions than at full light, as indicated by a significant interaction between pre-treatment and light in the light regime analysis (Table 5).

\section{Filipendula vulgaris and Helianthemum nummularium}

Irrespective of seed pre-treatment, final germination in both species tended to reach $30-50 \%$ across the various abiotic treatment combinations, but was lower in F. vulgaris for both untreated seeds and coldstratified seeds in various treatment combinations involving darkness (Fig. 1C). Raised levels of dark germination in F. vulgaris in response to $\mathrm{PEG}+\mathrm{GA}_{3}$ priming were reflected by a significant interaction between pre-treatment and light regime in the light regime analysis (Table 3 ). At the same time, at full 

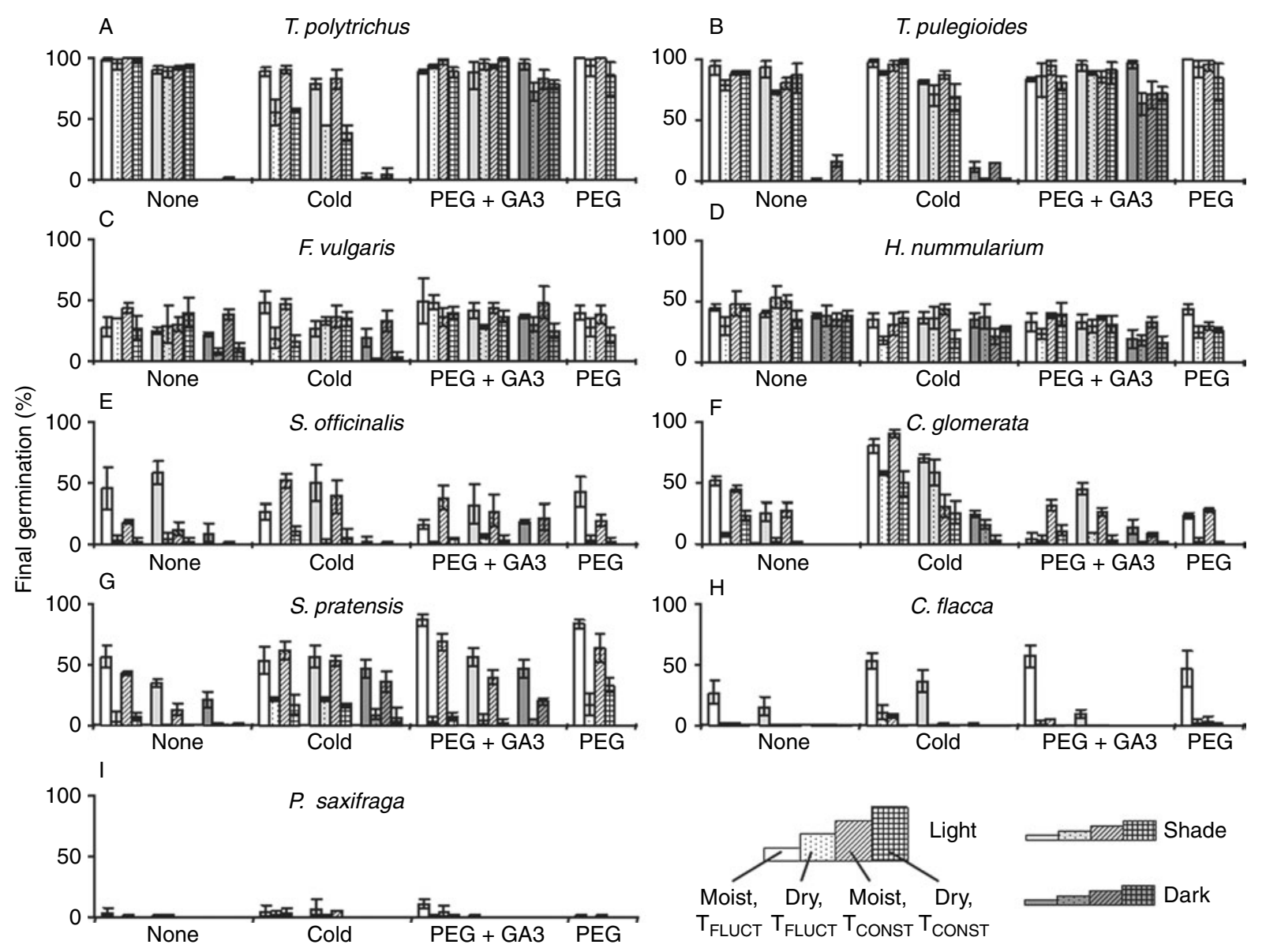

Figure 1. Percentage final germination of nine species of calcareous grassland under 12 different abiotic regimes, combining three light regimes with two different moisture levels and two temperature regimes, constant versus fluctuating. Results are shown for untreated seeds, cold-stratified seeds, seeds primed osmotically with a PEG solution containing GA , $_{3}$ and seeds primed osmotically with a PEG solution not containing $\mathrm{GA}_{3}$. Back-transformed means and standard errors are shown.

light, cold-stratification appeared to have induced an increased susceptibility to drought stress in F. vulgaris (Fig. 1C), reflected by a significant interaction between seed pre-treatment and moisture level (Table 2).

In $H$. nummularium, germination was not reduced by darkness. However, irrespective of abiotic conditions, final germination in this species was slightly - but nevertheless significantly - reduced both by cold-stratification and seed priming (Tables 2 and 3; Fig. 1D).

As expressed by lower $t_{50}$ values, germination of F. vulgaris was accelerated by seed priming, irrespective of whether $\mathrm{GA}_{3}$ was added to the PEG solution (Fig. 2C; see also Tables 4 and 5). At least in the fulllight regime, priming both with and without added $\mathrm{GA}_{3}$ also accelerated germination in $H$. nummularium (Fig. 2D, Table 4). Priming also mitigated the slowing down of germination in response to drought stress that was observed in untreated seeds (Fig. 2D), as underlined by a significant interaction between pre-treatment and moisture level in both analyses of $t_{50}$ data (Tables 4 and 5). At the same time, cold-stratification mitigated the deceleration of germination that was observed in untreated seeds in response to shading (Fig. 2D), and this was also reflected by a significant interaction between pre-treatment and light in the light regime analysis (Table 5).

\section{Stachys officinalis}

Germination of untreated seeds of S. officinalis was strongly reduced by constant temperature, by water potential reduction and by darkness, but not by shading (Fig. 1E). As indicated by significant interaction effects between pre-treatment and temperature regime (Tables 2 and 3), both cold-stratification as well as PEG $+\mathrm{GA}_{3}$ priming substituted for the temperature fluctuation requirement (Fig. 1E). In addition, PEG $+\mathrm{GA}_{3}$ priming promoted dark germination at the unreduced water potential, and this was reflected in the light regime analysis by a significant three-way interaction between pre-treatment, light and moisture (Table 3). 


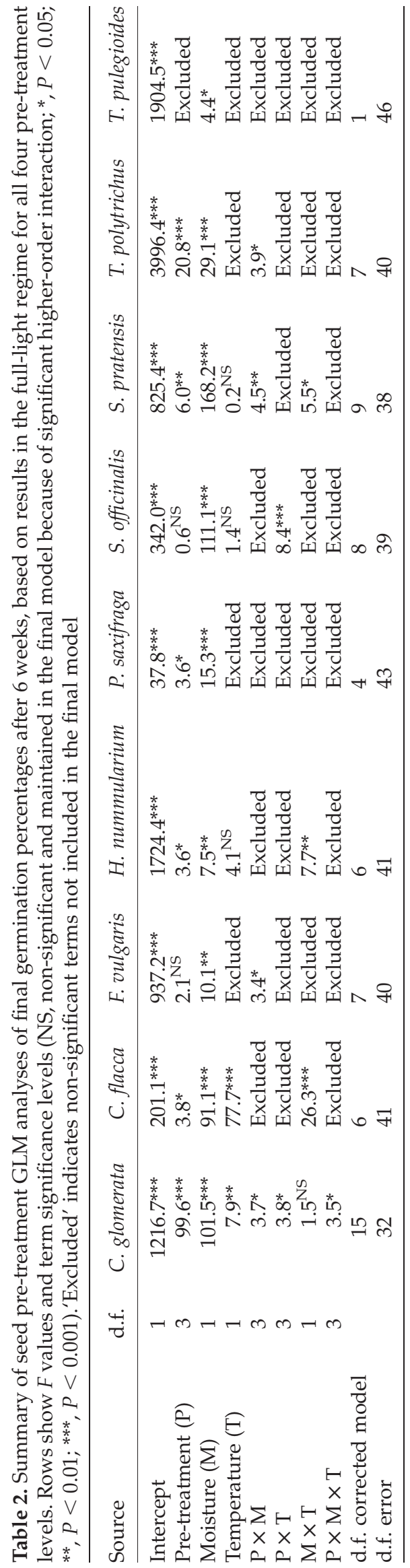

Whereas temperature fluctuation enhanced overall germination of $S$. officinalis, it did not affect germination speed as expressed by $t_{50}$ (Fig. 2E). Seed priming accelerated germination, irrespective of temperature regime or shading (Fig. 2E), as reflected by significant pre-treatment main effects in both analyses, combined with non-significant pre-treatment interactions with both light and temperature (Tables 4 and 5).

\section{Campanula glomerata and Succisa pratensis}

In both C. glomerata and S. pratensis, a combination of full light, temperature fluctuation, and unreduced water potential was most conducive to high final germination. However, even this optimal combination of abiotic factors resulted in a final germination of untreated seeds only slightly higher than $50 \%$ in both species (Fig. 1F, G). In both species, constant temperature only slightly reduced final germination, whereas both shading and reduced water potential resulted in a much stronger reduction (Fig. 1F, G).

In both species, at least one pre-treatment resulted in a marked increase in germination. In C. glomerata, final germination reached about $90 \%$ in the most optimal abiotic treatment in response to cold-stratification (Fig. 1F). Cold-stratification in this species also induced dark germination in a proportion of seeds, and also reduced the moisture requirement for germination, in particular in the shaded and dark treatments (Fig. 1F). This was also reflected in a highly significant interaction between pre-treatment, light regime and moisture regime in the light regime analysis (Table 3). Priming of C. glomerata seeds resulted in slightly lower final germination in the fulllight regime; however, $\mathrm{PEG}+\mathrm{GA}_{3}$ priming appeared to slightly enhance germination in the shade and dark treatments (Fig. 1F).

Final germination in $S$. pratensis was strongly enhanced by PEG $+\mathrm{GA}_{3}$ priming, but this was only observed at the unreduced water potential (Fig. 1G). By contrast, cold-stratification enhanced germination at both water potentials, although at the unreduced water potential, the effect was small in comparison to the effect of PEG $+\mathrm{GA}_{3}$ priming (Fig. 1G). Both coldstratification and $\mathrm{PEG}+\mathrm{GA}_{3}$ priming promoted dark germination in S. pratensis (Fig. 1G). The described pretreatment and abiotic responses are also reflected by the highly significant interactions between pre-treatment and moisture in the seed pre-treatment analysis (Table 2), and between pre-treatment, light and moisture in the light regime analysis (Table 3).

In C. glomerata, both cold-stratification and PEG $+\mathrm{GA}_{3}$ priming markedly reduced $t_{50}$, i.e. they accelerated seed germination (Fig. 2F), and this was also reflected by significant pre-treatment main and interaction effects (Tables 4 and 5). 
Table 3. Summary of light regime GLM analyses of final germination percentages after 6 weeks, based on results for three different light regimes in combination with three different pre-treatment levels, not including the 'PEG only' option. See Table 2 for notation

\begin{tabular}{|c|c|c|c|c|c|c|c|c|c|c|}
\hline Source & d.f. & C. glomerata & C. flacca & F. vulgaris & H. nummularium & P. saxifraga & S. officinalis & S. pratensis & T. polytrichus & T. pulegioides \\
\hline Intercept & 1 & $1634.9^{* * *}$ & $237.4^{* * *}$ & $1838.1^{* * *}$ & $3150.7^{* * *}$ & $51.8^{* * *}$ & $395.7^{* * *}$ & $1493.0^{* * *}$ & $6323.0^{* * *}$ & $3389.8^{* * *}$ \\
\hline Pre-treatment $(\mathrm{P})$ & 2 & $118.8^{* * *}$ & $10.0^{* * * *}$ & $12.6^{* * *}$ & $13.0^{*}$ & $3.7^{*}$ & $0.4^{\mathrm{NS}}$ & $51.0^{* * *}$ & $199.8^{* * *}$ & $41.6^{* * *}$ \\
\hline Light (L) & 2 & $178.4^{* * *}$ & $81.0^{* * *}$ & $16.6^{* * *}$ & $4.6^{*}$ & $16.7^{* * *}$ & $35.4^{* * *}$ & $42.9^{* * *}$ & $500.7^{* * *}$ & $222.2^{* * *}$ \\
\hline Moisture (M) & 1 & $134.2^{* * *}$ & $148.2^{* * *}$ & $24.2^{* * *}$ & $4.8^{*}$ & $19.1^{* * *}$ & $150.2^{* * *}$ & $402.5^{* * *}$ & $32.8^{* * *}$ & $19.6^{* * *}$ \\
\hline Temperature $(\mathrm{T})$ & 1 & $12.9^{* * *}$ & $124.6^{* * *}$ & Excluded & Excluded & $5.7^{*}$ & $0.2^{\mathrm{NS}}$ & $18.6^{* * *}$ & Excluded & Excluded \\
\hline $\mathrm{P} \times \mathrm{L}$ & 4 & $20.9^{* * *}$ & $3.6^{* *}$ & $2.5^{*}$ & Excluded & $3.5^{*}$ & $2.4^{\mathrm{NS}}$ & $3.3^{*}$ & $94.3^{* * *}$ & $38.7^{* * *}$ \\
\hline $\mathrm{P} \times \mathrm{M}$ & 2 & $1.7^{\mathrm{NS}}$ & $3.1^{\mathrm{NS}}$ & $3.6^{*}$ & Excluded & Excluded & $0.3^{\mathrm{NS}}$ & $11.2^{* * *}$ & $16.3^{* * *}$ & Excluded \\
\hline $\mathrm{P} \times \mathrm{T}$ & 2 & $14.1^{* * *}$ & Excluded & Excluded & Excluded & Excluded & $8.0^{* * *}$ & $2.0^{\mathrm{NS}}$ & Excluded & Excluded \\
\hline $\mathrm{L} \times \mathrm{M}$ & 2 & $7.3^{* *}$ & $38.6^{* * *}$ & $8.9^{* * *}$ & $0.7^{\mathrm{NS}}$ & $6.0^{* *}$ & $4.4^{*}$ & $9.1^{* * *}$ & $1.6^{\mathrm{NS}}$ & Excluded \\
\hline $\mathrm{L} \times \mathrm{T}$ & 2 & $16.4^{* * *}$ & $32.8^{* * *}$ & Excluded & $3.6^{*}$ & Excluded & $4.6^{*}$ & $4.0^{*}$ & Excluded & Excluded \\
\hline $\mathrm{M} \times \mathrm{T}$ & 1 & Excluded & $62.8^{* * *}$ & Excluded & $0.2^{\mathrm{NS}}$ & Excluded & $4.4^{*}$ & $10.1^{* *}$ & Excluded & Excluded \\
\hline $\mathrm{P} \times \mathrm{L} \times \mathrm{M}$ & 4 & $6.0^{* * *}$ & $2.7^{*}$ & $2.6^{*}$ & Excluded & Excluded & $2.7^{*}$ & $3.2^{*}$ & $4.5^{* *}$ & Excluded \\
\hline $\mathrm{P} \times \mathrm{L} \times \mathrm{T}$ & 4 & Excluded & Excluded & Excluded & Excluded & Excluded & Excluded & Excluded & Excluded & Excluded \\
\hline $\mathrm{P} \times \mathrm{M} \times \mathrm{T}$ & 2 & Excluded & Excluded & Excluded & Excluded & Excluded & Excluded & $4.8^{*}$ & Excluded & Excluded \\
\hline $\mathrm{L} \times \mathrm{M} \times \mathrm{T}$ & 2 & Excluded & $13.2^{* * *}$ & Excluded & $5.6^{* *}$ & Excluded & Excluded & Excluded & Excluded & Excluded \\
\hline $\mathrm{P} \times \mathrm{L} \times \mathrm{M} \times \mathrm{T}$ & 4 & Excluded & Excluded & Excluded & Excluded & Excluded & Excluded & Excluded & Excluded & Excluded \\
\hline d.f. corrected model & & 22 & 23 & 17 & 13 & 12 & 12 & 25 & 17 & 9 \\
\hline d.f. error & & 85 & 84 & 90 & 94 & 95 & 84 & 82 & 90 & 98 \\
\hline
\end{tabular}



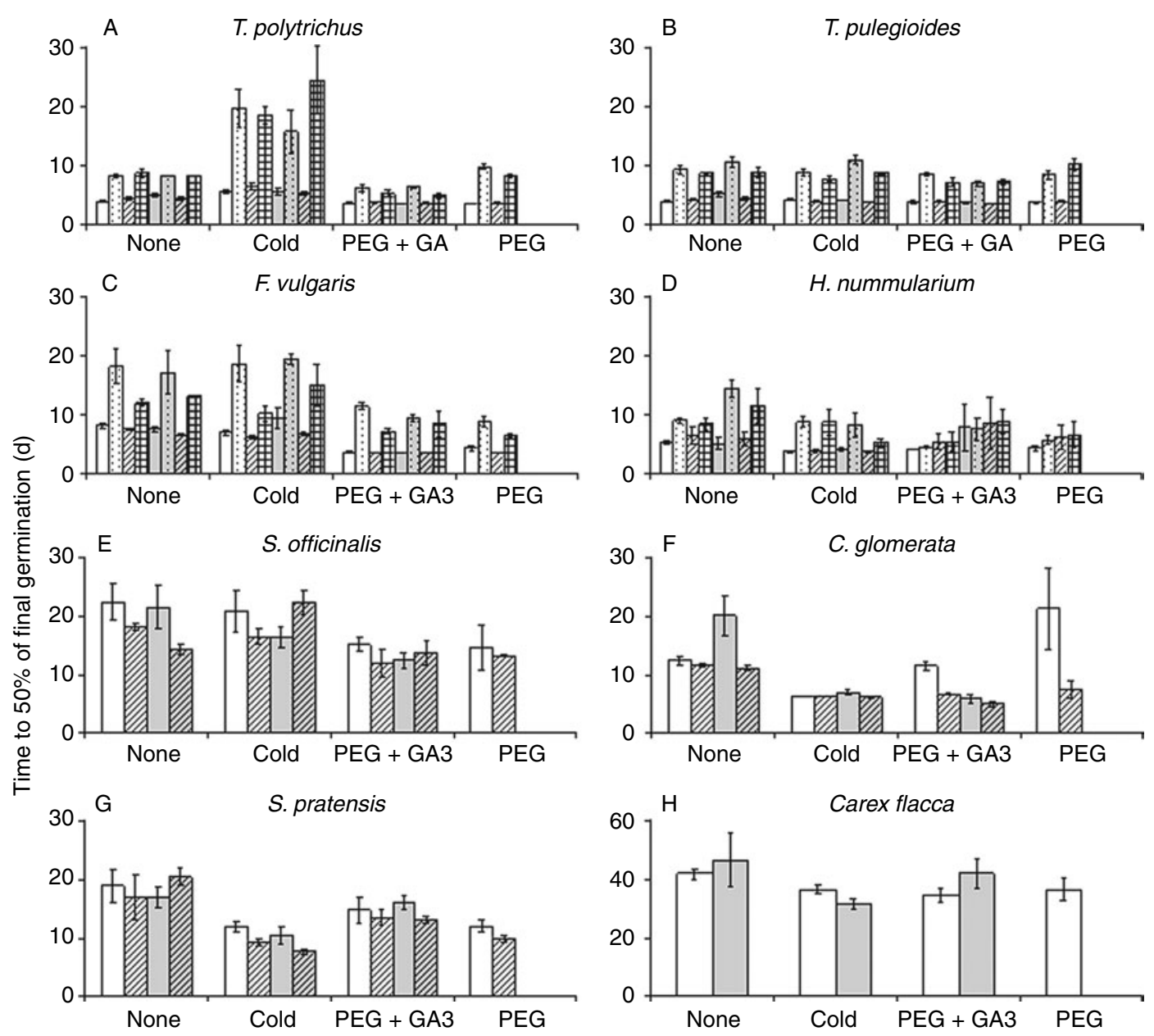

Figure 2. Time in days to $50 \%$ of final germination of eight species of calcareous grassland under 12 different abiotic regimes, combining two light regimes, full light and shade, with two different moisture levels and two temperature regimes, constant versus fluctuating. Results are shown for untreated seeds, cold-stratified seeds, seeds primed osmotically with a PEG solution containing $\mathrm{GA}_{3}$, and seeds primed osmotically with a PEG solution not containing $\mathrm{GA}_{3}$. Untransformed means and standard errors are shown. For the key see Fig. 1.

In S. pratensis, all pre-treatments resulted in faster germination, with PEG $+\mathrm{GA}_{3}$ priming being slightly less effective (Fig. 2G). This was reflected by significant pre-treatment effects on $t_{50}$ in both the seed pretreatment analysis (Table 4) and the light regime analysis (Table 5). At the same time, the absence of significant interactions between pre-treatment and abiotic factors (Tables 4 and 5) indicated that pretreatment effects on germination speed in this species occurred independent of abiotic regime.

Table 4. Summary of seed pre-treatment GLM analyses of $t_{50}$, based on results in the full-light regime for all four pre-treatment levels. See Table 2 for notation

\begin{tabular}{|c|c|c|c|c|c|c|c|c|c|}
\hline Source & d.f. & C. glomerata & C. flacca & F. vulgaris & H. nummularium & S. officinalis & S. pratensis & T. polytrichus & T. pulegioides \\
\hline Intercept & 1 & $10774.3^{* * *}$ & $478343.0^{* * *}$ & $21333.1^{* * *}$ & 15688 & $3455.7^{* * *}$ & $1277603.1^{* * *}$ & $89242.3^{* * *}$ & $67404.6^{* * *}$ \\
\hline Pre-treatment $(\mathrm{P})$ & 2 & $10.2^{* * *}$ & Excluded & $91.8^{* * *}$ & $5.3^{* *}$ & $4.4^{*}$ & $10.5^{* * *}$ & $82.8^{* * *}$ & Excluded \\
\hline Moisture (M) & 1 & Not tested & Not tested & $391.7^{* * *}$ & $21.8^{* * *}$ & Not tested & Not tested & $535.3^{* * *}$ & $707.3^{* * *}$ \\
\hline Temperature $(\mathrm{T})$ & 1 & $17.3^{* * *}$ & Not tested & $47.6^{* * *}$ & Excluded & Excluded & $7.4^{*}$ & $0.1^{\mathrm{NS}}$ & Excluded \\
\hline $\mathrm{P} \times \mathrm{M}$ & 2 & Not tested & Not tested & $6.2^{* *}$ & $4.9^{* *}$ & Not tested & Not tested & $7.4^{* * *}$ & Excluded \\
\hline $\mathrm{P} \times \mathrm{T}$ & 2 & $5.7^{* *}$ & Not tested & Excluded & Exclu & Excluded & Excluded & Excluded & Excluded \\
\hline $\mathrm{M} \times \mathrm{T}$ & 1 & Not tested & Not tested & $14.7^{* * *}$ & Excluded & Not tested & Not tested & $4.9^{*}$ & Excluded \\
\hline $\mathrm{P} \times \mathrm{M} \times \mathrm{T}$ & 2 & Not tested & Not tested & Excluded & Excluded & Not tested & Not tested & Exclu & Excluded \\
\hline d.f. corrected model & & 7 & 0 & 9 & 7 & 3 & 4 & 9 & 1 \\
\hline d.f. error & & 16 & 11 & 38 & 40 & 20 & 19 & 38 & 46 \\
\hline
\end{tabular}


Table 5. Summary of light regime GLM analyses of $t_{50}$, based on results for three different light regimes in combination with three different pre-treatment levels, not including the 'PEG only' option. See Table 2 for notation

\begin{tabular}{|c|c|c|c|c|c|c|c|c|c|}
\hline Source & d.f. & C. glomerata & C. flacca & F. vulgaris & H. nummularium & S. officinalis & S. pratensis & T. polytrichus & T. pulegioides \\
\hline Intercept & 1 & $43937.0^{* * *}$ & $51231669.2^{* * *}$ & $15308.1^{* * *}$ & $16130.9^{* * *}$ & $7952.9^{* * *}$ & $16067.6^{* * *}$ & $91559.9^{* * *}$ & $41208.1^{* * *}$ \\
\hline Pre-treatment $(\mathrm{P})$ & 2 & $89.5^{* * *}$ & Excluded & $103.7^{* * *}$ & $8.6^{* * *}$ & $9.1^{* * *}$ & $28.3^{* * *}$ & $154.9^{* * *}$ & $19.9^{* * *}$ \\
\hline Light $(\mathrm{L})$ & 2 & $9.8^{* *}$ & Excluded & $0.9^{\mathrm{NS}}$ & $1.4^{\mathrm{NS}}$ & Excluded & Excluded & Excluded & $2.0^{\mathrm{NS}}$ \\
\hline Moisture (M) & 1 & Not tested & Not tested & $348.2^{* * *}$ & $37.2^{* * *}$ & Not tested & Not tested & $440.6^{* * *}$ & $963.4^{* * *}$ \\
\hline Temperature (T) & 1 & $21.4^{* * *}$ & Not tested & $29.1^{* * *}$ & Excluded & Excluded & Excluded & Excluded & $11.4^{* *}$ \\
\hline $\mathrm{P} \times \mathrm{L}$ & 4 & $22.8^{* * *}$ & Excluded & $3.3^{*}$ & $3.4^{*}$ & Excluded & Excluded & Excluded & $5.4^{* *}$ \\
\hline $\mathrm{P} \times \mathrm{M}$ & 2 & Not tested & Not tested & $4.7^{*}$ & $5.1^{* *}$ & Not tested & Not tested & $3.5^{*}$ & Excluded \\
\hline $\mathrm{P} \times \mathrm{T}$ & 2 & $2.8^{\mathrm{NS}}$ & Not tested & Excluded & Excluded & Excluded & Excluded & Excluded & Excluded \\
\hline $\mathrm{L} \times \mathrm{M}$ & 2 & Not tested & Not tested & Excluded & Excluded & Not tested & Not tested & Excluded & Excluded \\
\hline $\mathrm{L} \times \mathrm{T}$ & 2 & $0.3^{\mathrm{NS}}$ & Not tested & Excluded & Excluded & Excluded & Excluded & Excluded & Excluded \\
\hline $\mathrm{M} \times \mathrm{T}$ & 1 & Not tested & Not tested & $8.4^{* *}$ & Excluded & Not tested & Not tested & Excluded & Excluded \\
\hline $\mathrm{P} \times \mathrm{L} \times \mathrm{M}$ & 4 & Not tested & Not tested & Excluded & Excluded & Not tested & Not tested & Excluded & Excluded \\
\hline $\mathrm{P} \times \mathrm{L} \times \mathrm{T}$ & 4 & $4.8^{*}$ & Not tested & Excluded & Excluded & Excluded & Excluded & Excluded & Excluded \\
\hline $\mathrm{P} \times \mathrm{M} \times \mathrm{T}$ & 2 & Not tested & Not tested & Excluded & Excluded & Not tested & Not tested & Excluded & Excluded \\
\hline $\mathrm{L} \times \mathrm{M} \times \mathrm{T}$ & 2 & Not tested & Not tested & Excluded & Excluded & Not tested & Not tested & Excluded & Excluded \\
\hline $\mathrm{P} \times \mathrm{L} \times \mathrm{M} \times \mathrm{T}$ & 4 & Not tested & Not tested & Excluded & Excluded & Not tested & Not tested & Excluded & Excluded \\
\hline d.f. corrected model & & 11 & 0 & 10 & 8 & 2 & 2 & 5 & 7 \\
\hline d.f. error & & 24 & 17 & 61 & 63 & 33 & 33 & 66 & 64 \\
\hline
\end{tabular}

\section{Carex flacca}

Notable germination of untreated C. flacca seeds occurred only at the higher of the two water potential levels, and only in the fluctuating temperature regime. Under these optimal conditions, germination after 6 weeks reached $27 \%$ in the fulllight regime, and $15 \%$ in the shade regime (Fig. $1 \mathrm{H}$ ). After 10 weeks, this had increased to $51 \%$ and $23 \%$, respectively (data not shown). Cold-stratification boosted germination both in the full-light and shade optimal abiotic combinations, but PEG seed priming - both with and without added $\mathrm{GA}_{3}$ - did so only at full light (Fig. 1H). None of the pre-treatments did, however, stimulate germination at the reduced water potential or at the constant temperature, and neither did they induce any dark germination (Fig. 1H). Accordingly, while pre-treatment interacted with light regime in the light regime analysis (Table 5), it showed no other significant interactions with abiotic factors in either of the two analyses (Tables 4 and 5).

A pre-treatment effect on $t_{50}$ of $C$. flacca fell short of significance in the light regime analysis $(P=0.072)$, although results suggest a mean reduction of $t_{50}$ of 6 days in response to cold-stratification (Fig. 2H).

\section{Pimpinella saxifraga}

Final germination of $P$. saxifraga was very low, but a slight increase was detected after cold-stratification (Fig. 1I; Table 3).

\section{Discussion}

Our investigation of abiotic germination requirements of calcareous grassland species illustrates the mechanisms that underlie spatial and temporal variation in germination niches thought to promote high species richness in this ecosystem (Grubb, 1977; Thompson et al., 1996). Previous research has identified a main axis describing a gradient in germination requirements, ranging from species that germinate indiscriminately soon after primary seed dispersal (e.g. many Poaceae and large-seeded dicots) to more temporally opportunistic species (e.g. many smallseeded dicots; Thompson et al., 1996). While one species (B. erecta) among those we tested germinated indiscriminately, the other nine species exhibited large variation in germination responses to treatments, which suggests the existence of further germination niche axes. In the following, we discuss abiotic germination niches of our species, the effects of seed pre-treatments, and the wider implications for ecological restoration.

\section{Abiotic germination niches}

Of all tested species, C. flacca had the most specific abiotic requirements for germination. Moderate drought stress effectively prevented its germination. Our results also confirmed strong requirements of light (Grime et al., 1981) and of temperature fluctuation (Thompson and Grime, 1983; Schütz and Rave, 1999), suggesting a germination preference for large vegetation gaps. Schütz and Rave (1999) showed that 
the requirement for temperature fluctuation is more absolute in C. flacca than in many other Carex species: In their study, C. flacca was one of very few species in which constant high temperature did not substitute for temperature fluctuation. In our study, 5 weeks of coldstratification promoted germination, but did not widen the range of abiotic conditions conducive to germination. Under field conditions, C. flacca is strictly spring-germinating (Thompson et al., 1996), suggesting a more absolute cold requirement than found in our study. However, in our study, germination of untreated $C$. flacca seeds may have been promoted by the extended storage period, as dry storage has been reported as beneficial for germinability of this species (Grime et al., 1981). Time to 50\% final germination appeared reduced in response to cold-stratification, but this was not significant, possibly due to comparatively low statistical power.

Due to their cold requirement, when introduced by sowing, the seeds of C. flacca require sufficient exposure to cold temperatures, either by sowing in autumn or by cold-stratification prior to sowing in spring. However, while cold-stratification usually promotes germination of $C$. flacca under abiotic conditions conducive to its germination, it did not appear to widen the narrow abiotic germination niche of this species. Even when cold-stratified, seeds have a strong requirement of high light and moisture levels, and of temperature fluctuation, which all have to be adequately met. Therefore, and as $C$. flacca has a very high potential for vegetative spread (Grime et al., 2007), introduction as small plants or vegetative fragments may be a good alternative when restoring populations of this species.

Four species were characterized by a very wide abiotic niche for germination. Irrespective of abiotic regime, untreated seeds of $F$. vulgaris and $H$. nummularium almost always showed $30-50 \%$ germination, with slightly lower levels of germination in those treatments that combined low water potential with darkness (Fig. 1C, D). By contrast, untreated seeds of the small-seeded $T$. polytrichus and T. pulegioides (Table 1) germinated nearly completely in full-light and shade treatments, but not in darkness. Final germination of all four species appeared uninfluenced by temperature fluctuation, and light requirement was relatively minimal, suggesting no adaptation to germinate only in larger gaps. In T. polytrichus, cold-stratification slowed down and reduced percentage germination at reduced water potential. This may be interpreted as a form of conditional dormancy that could increase fitness if dry periods were more frequent or more extended in spring than in autumn.

Cold-stratification did not increase germination in any of the four species, suggesting that they are not specialized to germinate in spring. In agreement with this, Stampfli and Zeiter (2008) found that both H. nummularium and T. pulegioides germinate throughout the cool season, i.e. from autumn to spring. Similarly, Thompson et al. (1996) showed that both $H$. nummularium and T. polytrichus emerge in autumn and spring. Finally, Partzsch (2008) found that seeds of F. vulgaris germinated readily shortly after fieldcollection without pre-treatment.

It appears unlikely that lack of germination explains the poor performance of these four species in restoration, although enhancement of germination in those species with incomplete germination might nonetheless boost seedling establishment. In F. vulgaris, this was achieved by seed priming. $H$. nummularium is characterized by physical seed dormancy (Table 1; see also Thanos et al., 1992), i.e. by initial seed-coat impermeability for water. While there are different seed pre-treatments available in this situation (Baskin and Baskin, 1998), this also explains why priming did not increase final germination, in spite of accelerating it. Seeds whose coats were already permeable germinated faster, but physically dormant seeds did not benefit. Negative effects of stratification and priming on final germination in $H$. nummularium did not depend on abiotic conditions, i.e. were unlikely to be due to narrowing of the abiotic window permissive to germination. As we did not test the viability of ungerminated seeds at the end of the experiment, we cannot preclude mortality during the pre-treatment phase.

Three species were intermediate in terms of abiotic germination-niche width. S. pratensis, C. glomerata and S. officinalis all germinated comparatively well under shaded conditions (for S. pratensis see also Grime et al., 1981), but at the same time had a relatively high moisture requirement. However, whereas the former two did not require temperature fluctuation, this was the case for S. officinalis (see Patzelt et al., 2001). All three species thus appear to have a lesser necessity for large gaps than C. flacca, although the requirement for temperature fluctuation in S. officinalis may suggest otherwise. For S. pratensis, our finding of germination under shaded conditions fits with the observation that establishment may even benefit from the presence of a plant canopy (Isselstein et al., 2002).

Cold-stratification promoted germination in C. glomerata and S. pratensis, implying specialization towards spring germination (for $S$. pratensis see Maas, 1989; Patzelt et al., 2001), but did not generally increase germination of $S$. officinalis which is early summer germinating (Patzelt et al., 2001).

Our results suggest that cold-stratification best improves establishment of C. glomerata and $S$. pratensis, and that seed priming can at least accelerate establishment of $S$. officinalis. Even when unaccompanied by an increase in overall germination, 
this may increase the ability to compete, e.g. with high densities of weed seedlings that can quickly establish on ex-arable land.

Low levels of $P$. saxifraga germination may, at least in part, have been due to many seeds either lacking a viable embryo, or having an underdeveloped one, not able to germinate prior to maturation in an imbibed state (= morphophysiological dormancy sensu Baskin and Baskin, 1998; see also Flemion and Henrickson, 1949), although decline in seed viability during seed storage prior to the study may also have contributed. Cold-stratification may thus only affect seeds with more or less mature embryos, resulting in weak stimulation of germination. This agrees with the observation that $P$. saxifraga mainly emerges in spring (Stampfli and Zeiter, 2008). Morphophysiological dormancy is characteristic for many Apiaceae species, and these species often appear only in the second year after sowing in field experiments (Silvertown and Tremlett, 1989). To break their dormancy, either an extended period of cold-stratification, or of warm-stratification followed by cold-stratification, is suggested (Baskin and Baskin, 1998).

\section{Wider implications for restoration}

In calcareous grassland, physical hazards such as drought are a major cause of seedling mortality, and shelter provided by neighbouring plants may, for many species, more than outweigh the potential disadvantage of seedlings having to compete with these plants (Ryser, 1993). However, the balance between facilitative and competitive effects will be different under the more fertile conditions usually encountered at grassland restoration sites (Bruno et al., 2003; Wagner, 2004). Even those species requiring relatively small gaps for regeneration in unimproved grassland may thus depend on pre-sowing disturbance in the denser swards of restoration sites. Interestingly, a gradient in seed and germination attributes quite similar to the one identified by Thompson et al. (1996) - from species germinating indiscriminately and rapidly to species with very specific abiotic requirements - has also been identified for species replacement during conversion of productive grassland to unproductive grassland (Olff et al., 1994). This may suggest that immediate germination could be a better adaptation to more productive conditions. Accordingly, species known to establish poorly when introduced in the productive early stages of restoration may do so because their specific requirements for germination and/or seedling establishment are not met at that stage. This would confirm the argument that abiotic features cannot be ignored when dealing with questions of biotic composition in restoration (Hobbs and Norton, 2004). Such effects may be most pronounced in species with very strict abiotic requirements and a very narrow seasonal window for germination, such as C. flacca in our study. For such species, sowing at a later stage of restoration may work better (Pywell et al., 2007), although for species with a known capacity for vegetative spread, early introduction by planting might also yield satisfactory results.

Our results suggest that seed pre-treatments can improve rates and overall levels of germination in species characterized by opportunistic germination, enabling them to better exploit the short temporal window of opportunity for establishment associated with pre-sowing disturbance. While we cannot prove this, it seems likely that the stimulation of dark germination after PEG $+\mathrm{GA}_{3}$ priming, observed in several species, was caused by the addition of $\mathrm{GA}_{3}$. Similar effects have been observed in other species (Finch-Savage, 1991; Finch-Savage et al., 1991). Otherwise, we found little evidence for positive effects on seed germination of adding $\mathrm{GA}_{3}$ to the priming solution. We would thus not generally recommend such a combination, especially as $\mathrm{GA}_{3}$, at higher concentrations, can induce development of morphologically abnormal seedlings with reduced fitness (e.g. Rogis et al., 2004). We tested only a limited range of pre-treatments, and variation of factors, such as pre-treatment duration, PEG solution concentration, temperature during the pre-treatment phase or use of other priming methods, may increase pre-treatment efficiency. In some species, dry storage at room temperature may be sufficient to overcome dormancy, as found in previous studies for C. flacca (Grime et al., 1981) and for S. pratensis (Kotorová and Lepš, 1999).

Widening of the abiotic germination niche by seed pre-treatments may also enhance establishment success. Even when such widening may be accompanied by an increased risk of seedling mortality, e.g. by dessication after relaxation of the moisture requirement for germination, this risk may be well worth taking given that the temporal window of opportunity for seedling establishment associated with pre-sowing disturbance is often short-lived. While it remains to be demonstrated in field experiments that the most promising pretreatments can indeed increase establishment success under field conditions, it seems likely that, eventually, a deeper knowledge of species-specific germination niches and how these can be modified by seed pre-treatments may help to optimize the success of introduction by sowing in restoration. Further, such knowledge may also help to identify species for which sowing at a later stage or planting may represent a more viable strategy than sowing in the initial stage of restoration. 


\section{Acknowledgements}

Sam Amy, Jodey Peyton, Sarah Hulmes and Lucy Hulmes helped with seedling counts. Charles George tested the effects of the HDPE shade netting on light quality. Karsten Schönrogge provided use of incubators. We would also like to acknowledge the helpful comments made by the referees and handling editor. This study was funded by the NERC Centre for Ecology \& Hydrology.

\section{References}

Adegbuyi, E., Cooper, S.R. and Don, R. (1981) Osmotic priming of some herbage grass seed using polyethylene glycol (PEG). Seed Science and Technology 9, 867-878.

Angevine, M.W. and Chabot, B.F. (1979) Seed germination syndromes in higher plants. pp. 188-206 in Solbrig, O.T.; Jain, S.; Johnson, G.B.; Raven, P.H. (Eds) Topics in plant population biology. New York, Columbia University Press.

Bakker, J.P. (1989) Nature management by grazing and cutting. Dordrecht, Kluwer.

Barbaro, L., Dutoit, T. and Cozic, P. (2001) A six-year experimental restoration of biodiversity by shrubclearing and grazing in calcareous grasslands of the French Prealps. Biodiversity and Conservation 10, 119-135.

Baskin, C.C. and Baskin, J.M. (1998) Seeds: Ecology, biogeography, and evolution of dormancy and germination. San Diego, Academic Press.

Bossuyt, B., Butaye, J. and Honnay, O. (2006) Seed bank composition of open and overgrown calcareous grassland soils - a case study from Southern Belgium. Journal of Environmental Management 79, 364-371.

Braithwaite, M.E., Ellis, R.W. and Preston, C.D. (2006) Change in the British flora 1987-2004. London, Botanical Society of the British Isles.

Bruno, J.F., Stachowicz, J.J. and Bertness, M.D. (2003) Inclusion of facilitation into ecological theory. Trends in Ecology and Evolution 18, 119-125.

Bruun, H.H. (2000) Patterns of species richness in dry grassland patches in an agricultural landscape. Ecography 23, 641-650.

Bullock, J.M. (2000) Gaps and seedling colonization. pp. 375-395 in Fenner, M. (Ed.) Seeds: The ecology of regeneration in plant communities (2nd edition). Wallingford, CABI Publishing.

Cavers, P.B., Qaderi, M.M., Manku, R. and Downs, M.P. (2000) Intermittent germination: causes and ecological implications. pp. 363-374 in Black, M.; Bradford, K.J.; Vázquez-Ramos, J. (Eds) Seed biology: Advances and applications. Wallingford, CABI Publishing.

Crawley, M.J. (2005) Statistics: An introduction using $R$. Chichester, Wiley.

Davies, A. and Waite, S. (1998) The persistence of calcareous grassland species in the soil seed bank under developing and established scrub. Plant Ecology 136, 27-39.

Davies, A., Dunnett, N.P. and Kendle, T. (1999) The importance of transplant size and gap width in the botanical enrichment of species-poor grasslands in Britain. Restoration Ecology 7, 271-280.

Edwards, A.R., Mortimer, S.R., Lawson, C.S., Westbury, D.B., Harris, S.J., Woodcock, B.A. and Brown, V.K.
(2007) Hay strewing, brush harvesting of seed and soil disturbance as tools for the enhancement of botanical diversity in grasslands. Biological Conservation 134, 372-382.

Emorsgate Seeds (2010) Succisa pratensis - Devil's-bit scabious. http://wildseed.co.uk/species/view / 137 (accessed on 20 May 2010).

Evans, C.E. and Etherington, J.R. (1990) The effect of soil water potential on seed germination of some British plants. New Phytologist 115, 539-548.

Fagan, K.C., Pywell, R.F., Bullock, J.M. and Marrs, R.H. (2008) Do restored calcareous grasslands on former arable fields resemble ancient targets? The effect of time, methods and environment on outcomes. Journal of Applied Ecology 45, 1293-1303.

Fagan, K.C., Pywell, R.F., Bullock, J.M. and Marrs, R.H. (2010) The seed banks of English lowland calcareous grasslands along a restoration chronosequence. Plant Ecology 208, 199-211.

Fenner, M. (1978) A comparison of the abilities of colonizers and closed-turf species to establish from seed in artificial swards. Journal of Ecology 66, 953-963.

Finch-Savage, W.E. (1991) Development of bulk priming/ plant growth regulator seed treatments and their effect on the seedling establishment of four bedding plant species. Seed Science and Technology 19, 477-485.

Finch-Savage, W.E., Gray, D. and Dickson, G.M. (1991) Germination responses of seven bedding plant species to environmental conditions and gibberellic acid. Seed Science and Technology 19, 487-494.

Fischer, M. and Stöcklin, J. (1997) Local extinctions of plants in remnants of extensively used calcareous grasslands 1950-1985. Conservation Biology 11, 727-737.

Flemion, F. and Henrickson, E.T. (1949) Further studies on the occurrence of embryoless seeds and immature embryos in the Umbelliferae. Contributions from Boyce Thompson Institute 15, 291-297.

Galatowitsch, S. (2008) Seedling establishment in restored ecosystems. pp. 352-370 in Leck, M.A.; Parker, V.T.; Simpson, R.L. (Eds) Seedling ecology and evolution. Cambridge, Cambridge University Press.

Gibson-Roy, P., Delpratt, J. and Moore, G. (2007) Restoring the Victorian Western (Basalt) Plains grassland. 1. Laboratory trials of viability and germination, and the implications for direct seeding. Ecological Management and Restoration 8, 114-122.

Grime, J.P., Mason, G., Curtis, A.V., Rodman, J., Band, S.R., Mowforth, M.A.G., Neal, A.M. and Shaw, S. (1981) A comparative study of germination characteristics in a local flora. Journal of Ecology 69, 1017-1059.

Grime, J.P., Hodgson, J.G. and Hunt, R. (2007) Comparative plant ecology: A functional approach to common British species. Dalbeattie, Castlepoint Press.

Grubb, P.J. (1977) The maintenance of species-richness in plant communities: the importance of the regeneration niche. Biological Reviews 52, 107-145.

Gustafson, D.J., Gibson, D.J. and Nickrent, D.L. (2004) Competitive relationships of Andropogon gerardii (Big Bluestem) from remnant and restored native populations and selected cultivars. Functional Ecology 18, 451-457.

Halmer, P. (2004) Methods to improve seed performance in the field. pp. 125-166 in Benech-Arnold, R.L.; Sánchez, R.A. (Eds) Handbook of seed physiology - applications to agriculture. Binghamton, Haworth Press. 
Hardegree, S.P. and Emmerich, W.E. (1990) Effect of polyethylene glycol exclusion on the water potential of solution-saturated filter paper. Plant Physiology 92, $462-466$.

Hedberg, P. and Kotowski, W. (2010) New nature by sowing? The current state of species introduction in grassland restoration, and the road ahead. Journal for Nature Conservation 18, 304-308.

Helm, A., Hanski, I. and Pärtel, M. (2006) Slow response of plant species richness to habitat loss and fragmentation. Ecology Letters 9, 72-77.

Hillier, S.H., Walton, D.W.H. and Wells, D.A. (1990) Calcareous grasslands: Ecology and management. Bluntisham, Bluntisham Books.

Hitchmough, J., Paraskevopoulou, A. and Dunnett, N. (2008) Influence of grass suppression and sowing rate on the establishment and persistence of forb dominated urban meadows. Urban Ecosystems 11, 33-44.

Hobbs, R.J. and Norton, D.A. (2004) Ecological filters, thresholds, and gradients in resistance to ecosystem reassembly. pp. 72-95 in Temperton, V.M.; Hobbs, R.J.; Nuttle, T.; Halle, S. (Eds) Assembly rules and restoration ecology: Bridging the gap between theory and practice. Washington, Island Press.

Hodgson, J.G. (1989) Selecting and managing plant materials used in habitat construction. pp. 45-67 in Buckley, G.P. (Ed.) Biological habitat reconstruction. London, Belhaven.

Hofmann, M. and Isselstein, J. (2004) Seedling recruitment on agriculturally improved mesic grassland: the influence of disturbance and management schemes. Applied Vegetation Science 7, 193-200.

Hölzel, N. and Otte, A. (2003) Restoration of a speciesrich flood meadow by topsoil removal and diaspore transfer with plant material. Applied Vegetation Science 6, 131-140.

Isselstein, J., Tallowin, J.R.B. and Smith, R.E.N. (2002) Factors affecting seed germination and seedling establishment of fen-meadow species. Restoration Ecology 10, 173-184.

Kahmen, S. and Poschlod, P. (2008) Does germination success differ with respect to seed mass and germination season? Experimental testing of plant functional trait responses to grassland management. Annals of Botany 101, 541-548.

Kotorová, I. and Lepš, J. (1999) Comparative ecology of seedling recruitment in an oligotrophic wet meadow. Journal of Vegetation Science 10, 175-186.

Liu K., Eastwood R.J., Flynn S., Turner R.M. and Stuppy W.H. (2008) Seed Information Database (release 7.1, May 2008). Available at http:/ / www.kew.org/data / sid (accessed on 22 February 2010).

Maas, D. (1989) Germination characteristics of some plant species from calcareous fens in southern Germany and their implications for the seed bank. Holarctic Ecology 12, 337-344.

Manchester, S.J., McNally, S., Treweek, J.R., Sparks, T.H. and Mountford, J.O. (1999) The cost and practicality of techniques for the reversion of arable land to lowland wet grassland - an experimental study and review. Journal of Environmental Management 55, 91-109.

Michel, B.E. and Radcliffe, D. (1995) A computer program relating solute potential to solution composition for five solutes. Agronomy Journal 87, 126-130.
Olff, H., Pegtel, D.M., van Groenendael, J.M. and Bakker, J.P. (1994) Germination strategies during grassland succession. Journal of Ecology 82, 69-77.

Partzsch, M. (2008) Welchen Einfluss haben Temperatur und Azidität der Bodenlösung auf die Keimungsbiologie ausgewählter xerothermer Graslandarten? Hercynia N.F. 41, 239-252.

Patzelt, A., Wild, U. and Pfadenhauer, J. (2001) Restoration of wet fen meadows by topsoil removal: vegetation development and germination biology of fen species. Restoration Ecology 9, 127-136.

Pigott, C.D. (1955) Thymus L. Journal of Ecology 43, 365-387.

Pywell, R.F., Bullock, J.M., Hopkins, A., Walker, K.J., Sparks, T.H., Burke, M.J.W. and Peel, S. (2002) Restoration of species-rich grassland on arable land: assessing the limiting processes using a multi-site experiment. Journal of Applied Ecology 39, 294-309.

Pywell, R.F., Bullock, J.M., Roy, D.B., Warman, L., Walker, K.J. and Rothery, P. (2003) Plant traits as predictors of performance in ecological restoration. Journal of Applied Ecology 40, 65-77.

Pywell, R.F., Bullock, J.M., Tallowin, J.B., Walker, K.J., Warman, E.A. and Masters, G. (2007) Enhancing diversity of species-poor grasslands: an experimental assessment of multiple constraints. Journal of Applied Ecology 44, 81-94.

R Development Core Team (2009) R: A language and environment for statistical computing. Vienna, R Foundation for Statistical Computing.

Reckinger, C., Colling, G. and Matthies, D. (2010) Restoring populations of the endangered plant Scorzonera humilis: influence of site conditions, seed source, and plant stage. Restoration Ecology 18, 904-913.

Rodwell, D.S. (1992) British plant communities, Vol. 3. Grasslands and montane communities. Cambridge, Cambridge University Press.

Rogis, C., Gibson, L.R., Knapp, A.D. and Horton, R. (2004) Can solid matrix priming with $\mathrm{GA}_{3}$ break seed dormancy in eastern gamagrass? Journal of Range Management 57, 656-660.

Ryser, P. (1993) Influences of neighbouring plants on seedling establishment in limestone grassland. Journal of Vegetation Science 4, 195-202.

Schütz, W. (2000) The importance of seed regeneration strategies for the persistence of species in the changing landscape of Central Europe. Zeitschrift für Ökologie und Naturschutz 9, 73-83.

Schütz, W. and Rave, G. (1999) The effect of cold stratification and light on the seed germination of temperate sedges (Carex) from various habitats and implications for regenerative strategies. Plant Ecology $144,215-230$.

Silvertown, J. (1980) Leaf-canopy-induced seed dormancy in a grassland flora. New Phytologist 85, 109-118.

Silvertown, J. and Tremlett, M. (1989) Interactive effects of disturbance and shade upon colonization of grassland: an experiment with Anthriscus sylvestris (L.) Hoffm., Conium maculatum L., Daucus carota L., and Heracleum sphondylium L. Functional Ecology 3, 229-235.

Stace, C. (1997) New flora of the British Isles (2nd edition). Cambridge, Cambridge University Press.

Stampfli, A. and Zeiter, M. (1999) Plant species decline due to abandonment of meadows cannot easily be reversed 
by mowing. A case study from the southern Alps. Journal of Vegetation Science 10, 151-164.

Stampfli, A. and Zeiter, M. (2008) Mechanisms of structural change derived from patterns of seedling emergence and mortality in a semi-natural meadow. Journal of Vegetation Science 19, 563-574.

Tallowin, J.R.B., Rook, A.J. and Brookman, S.K.E. (1994) The effects of osmotic pre-sowing treatment on laboratory germination in a range of wild flower species. Annals of Applied Biology 124, 363-370.

Taylor, F.J. (1956) Carex flacca Schreb. Journal of Ecology 44, 281-290.

Thanos, C.A., Georghiou, K., Kadis, C. and Pantazi, C. (1992) Cistaceae: a plant family with hard seeds. Israel Journal of Botany 41, 251-263.

Thompson, K. and Grime, J.P. (1983) A comparative study of germination responses to diurnally-fluctuating temperatures. Journal of Applied Ecology 20, 141-156.

Thompson, K., Hillier, S.H., Grime, J.P., Bossard, C.C. and Band, S.R. (1996) A functional analysis of a limestone grassland community. Journal of Vegetation Science 7, 371-380.

UK Biodiversity Group (1998) UK Biodiversity Group Tranche 2 Action Plans - Volume II: Terrestrial and freshwater habitats. Peterborough, English Nature.
Wagner, M. (2004) The roles of seed dispersal ability and seedling salt tolerance in community assembly of a severely degraded site. pp. 266-284 in Temperton, V.M.; Hobbs, R.J.; Nuttle, T.; Halle, S. (Eds) Assembly rules and restoration ecology: Bridging the gap between theory and practice. Washington, Island Press.

Walker, K.J., Stevens, P.A., Stevens, D.P., Mountford, J.O., Manchester, S.J. and Pywell, R.F. (2004) The restoration and re-creation of species-rich lowland grassland on land formerly managed for intensive agriculture in the UK. Biological Conservation 119, 1-18.

Wallin, L., Svensson, B.M. and Lönn, M. (2009) Artificial dispersal as a restoration tool in meadows: sowing or planting? Restoration Ecology 17, 270-279.

WallisDeVries, M.F., Poschlod, P. and Willems, J.H. (2002) Challenges for the conservation of calcareous grasslands in northwestern Europe: integrating the requirements of flora and fauna. Biological Conservation 104, 265-273.

Washitani, I. and Masuda, M. (1990) A comparative study of the germination characteristics of seeds from a moist tall grassland community. Functional Ecology 4, 543-557.

Wells, T.C.E., Cox, R. and Frost, A. (1989) Diversifying grasslands by introducing seed and transplants into existing vegetation. pp. 283-298 in Buckley, G.P. (Ed.) Biological habitat reconstruction. London, Belhaven. 